\title{
Envelhecimento acelerado e ocorrência de fungos em duas cultivares de soja
}

\author{
Accelerated aging test and occurrence of fungi \\ in two soybean cultivars
}

\author{
Tereza Cristina de Carvalho ${ }^{1 *}$; Ana Dionisia da Luz Coelho Novembre ${ }^{2}$; \\ Maria Heloisa Duarte Moraes ${ }^{3}$; Bruna Gagliardi ${ }^{4}$
}

\begin{abstract}
Resumo
O objetivo dessa pesquisa foi verificar o controle de patógenos em sementes de duas cultivares de soja, pelo teste de envelhecimento acelerado. O experimento foi realizado nos laboratórios de Sementes do Departamento de Produção Vegetal e no de Patologia de Sementes do Departamento de Entomologia, Fitopatologia e Zoologia Agrícola da USP-ESALQ, em Piracicaba, SP. Utilizaram-se sementes de duas cultivares de soja (Embrapa 48 e FTS Águia). As sementes foram colhidas, manual e mecanicamente, com $18 \%, 15 \%$ e $12 \%$ de água e avaliadas, após a colheita quanto ao teor de água. Após a secagem, a qualidade das sementes foi determinada pelos testes de germinação, emergência de plântula, envelhecimento acelerado e sanidade. Houve redução da incidência de patógenos nas sementes de soja, das cultivares Embrapa 48 e FTS Águia, em função das condições de umidade relativa e temperatura do ar que são utilizadas no teste de envelhecimento acelerado, especialmente para as sementes da cultivar FTS Águia.
\end{abstract}

Palavras-chave: Glycine max, armazenamento, germinação, sanidade

\begin{abstract}
The aim of this study was to investigate the pathogens control in seeds of two soybean cultivars by the accelerated aging test. The experiment was conducted in the laboratories of the Department of Crops Production and Department of Entomology, Plant Pathology and Agricultural Zoology (USP-ESALQ), both from the Escola Superior de Agricultura Luiz de Queiroz, University of São Paulo in Piracicaba, SP. For this we used seeds of two soybean cultivars (Embrapa 48 and FTS Águia). Seeds were harvested manually and mechanically, with $18 \%, 15 \%$ and $12 \%$ water and, immediately after harvest, evaluated for water content. After drying, the quality of the seeds was determined by germination test, seedling emergence, accelerated aging and health test. The incidence of pathogens in soybean seeds reduced in cultivar Embrapa 48 and FTS Águia, depending on the conditions of relative humidity and air temperature that were used in the accelerated aging test, especially for the seeds of cultivar FTS Águia. Key words: Glycine max, storage, germination, health
\end{abstract}

\footnotetext{
${ }^{1}$ Eng. Agr., M.Sc., Aluna de pós-graduação, Departamento de Fitotecnia e Fitossanitarismo, Setor de Ciências Agrárias da Universidade Federal do Paraná, UFPR, Rua dos Funcionários, 1540, CEP: 80035-050, Curitiba. E-mail: tcdcarva@gmail.com

${ }^{2}$ Eng. Agr., Prof. a Dra., Departamento de Produção Vegetal, Universidade Estadual de São Paulo, USP/ESALQ, Caixa postal 9, 13418-900. Piracicaba. E-mail: adlcnove@esalq.usp.br

${ }^{3}$ Eng. Agr., Dra., Departamento Entomologia, Fitopatologia e Zoologia Agrícola, USP/ESALQ, Piracicaba. E-mail: mhdmorae@ esalq.usp.br

${ }^{4}$ Eng. Agr., M.Sc., Departamento de Produção Vegetal, USP/ESALQ, Piracicaba. E-mail: brugagliardi@gmail.com

* Autor para correspondência
} 
A produção de sementes com alta qualidade é uma exigência do mercado. Entre os atributos que definem a qualidade das sementes tem-se o genético, sendo formado por um conjunto de características atribuídas às sementes na fase de melhoramento e, o sanitário, que pode ser controlado, como exemplo, por técnicas que visem à diminuição da incidência de microrganismos.

As cultivares de sementes de soja têm diferenças em relação à composição e à estrutura dos tegumentos, diferenças estas, que podem resultar em sementes de maior ou menor qualidade. Obando Flor (2004) relatou que uma característica relevante em sementes de soja, que confere menor sensibilidade do tecido à injúria mecânica e que protege a parede celulósica do ataque de microrganismos, é a lignificação do tegumento. Segundo França Neto et al. (2006) a utilização de cultivares de soja com mais de $5 \%$ de lignina no tegumento das sementes tem propiciado a produção de sementes de melhor qualidade.

Mesmo em sementes de alta qualidade, muitos patógenos, principalmente fungos podem estar associados às sementes afetando a germinação e o vigor das plântulas, resultando em reduções da produtividade das plantas (SINCLAIR, 1991). O uso de técnicas alternativas no controle de fungos transmitidos por sementes vem sendo aplicado no processo de produção. De Leon e Grudloyma, (1994), observaram que a técnica da utilização de calor seco ou úmido, tem sido eficiente no controle de fungos transmitidos por sementes de milho, apresentado resultados promissores na sanidade das sementes. Raju e Sivaprakasan (1989) com o uso da termoterapia no controle de fungos que contaminavam superficialmente sementes de repolho, constataram redução da incidência de patógenos, aumento no poder germinativo e melhor expressão do vigor das sementes.

Com base nessas considerações, o objetivo dessa pesquisa foi verificar o controle de patógenos em sementes de soja, das cultivares Embrapa 48 e FTS Águia, pelo teste de envelhecimento acelerado.
Foram utilizadas para o estudo sementes de soja de duas cultivares, FTS Águia e Embrapa 48, que foram avaliadas, quanto aos teores de lignina do tegumento, pelo método indicado por Alvarez et al. (1997). As sementes da cultivar FTS Águia tinham $8,08 \%$ de lignina e foram consideradas como mais resistentes ao dano mecânico e menos sensível a incidência de patógenos, portanto de maior qualidade, em relação às sementes da cultivar Embrapa 48, que tinham 6,96\% de lignina. Estas sementes foram semeadas em área experimental do Departamento de Produção Vegetal, da Escola Superior de Agricultura Luiz de Queiroz, da Universidade de São Paulo, em Piracicaba, São Paulo, na safra 2007/2008; sendo a produção de sementes obtidas, utilizadas na referida pesquisa.

Para o experimento em campo foram instaladas 36 parcelas, compreendendo, três repetições (blocos) para cada cultivar, teor de água das sementes e colheitas manual e mecânica. As parcelas $(7,0 \mathrm{~m} x$ $4,5 \mathrm{~m}$ ) foram constituídas por dez linhas, com sete metros de comprimento, espaçadas de $0,45 \mathrm{~m}$; a área útil de colheita de cada parcela foram as seis linhas centrais e os cinco metros centrais de cada linha. O preparo do solo, a adubação, a irrigação e o controle fitossanitário e de plantas invasoras foram efetuados conforme as recomendações para a cultura da soja indicadas pela EMBRAPA (2006).

As sementes foram colhidas de forma manual e mecânica em três épocas distintas. A determinação da época da colheita foi através de coletas diárias (períodos da manhã e da tarde) de amostras de sementes em pontos aleatórios da área de produção, sendo as amostras submetidas à determinação do teor de água (BRASIL, 2009). No momento da colheita, para a cultivar Embrapa 48 as sementes colhidas manualmente tinham $18,4 \%, 14,4 \%$ e $11,6 \%$ de água e as mecanicamente 20,2\%, 15,9\% e $12 \%$ e para a cultivar FTS Águia as sementes colhidas manualmente tinham 17,5\%, 14,2\% e $11,4 \%$ de água e as mecanicamente $17,9 \%, 14,7 \%$ e $12,7 \%$. 
Após a secagem, as sementes foram avaliadas quanto ao teor de água e à germinação (BRASIL, 2009) e pelos testes de envelhecimento acelerado, de emergência de plântula (KRZYZANOWSKI; FRANÇA NETO; HENNING, 1991) e de sanidade (BRASIL, 2009).

Os dados obtidos em cada teste foram analisados de acordo com delineamento inteiramente casualizado, separadamente para cada cultivar e teste conduzido. Os resultados dos testes foram transformados em arco seno $\sqrt{ } \mathrm{x} / 100$, empregando o sistema de análise estatística para microcomputadores SANEST. As médias foram comparadas pelo teste de Tukey $(\mathrm{P} \leq 0,05)$.

Com base nos dados referentes ao teor de água, obtido após a secagem das sementes, das cultivares Embrapa 48 e FTS Águia (Tabela 1), as médias dos seis tratamentos estudados apresentaram valores similares. O conhecimento do teor de água das sementes é importante para a execução de testes, pois a uniformização do teor de água das sementes é imprescindível para a confiabilidade das avaliações (MARCOS FILHO; CICERO; SILVA, 1987).

Para as sementes da cultivar Embrapa 48, logo após a colheita (Tabela 1) apenas as sementes colhidas à maquina com $12 \%$ de água, apresentaram germinação acima de $80 \%$, padrão mínimo para comercialização de sementes de soja estabelecido pelo MAPA. Enquanto para as sementes da cultivar FTS Águia (Tabela 1) todos os tratamentos, apresentaram poder germinativo acima de $80 \%$. Os resultados do teste de sanidade (Tabela 2) indicaram que as sementes da cultivar Embrapa 48 tiveram maior incidência de fungos o que, provavelmente, tenha sido uma das causas do baixo potencial germinativo dessas sementes. Outra hipótese é de que o tegumento das sementes da cultivar FTS
Águia apresente um teor maior de lignina quando comparado ao das sementes da cultivar Embrapa 48; essa diferença confere às sementes melhor proteção em relação aos microrganismos (OBANDO FLOR et al., 2004).

Ao examinar a Tabela 1, verifica-se que o teste de emergência de plântula em areia, para as sementes da cultivar Embrapa 48 e FTS Águia, apresentou médias superiores às observadas no teste de germinação. Resultados semelhantes foram obtidos por Braccini et al. (1994) que verificaram, também, valores significativamente superiores de viabilidade das sementes de soja, de diferentes genótipos, no teste de emergência de plântula em areia em relação aos obtidos no de germinação. Esse resultado está relacionado à infecção das sementes por Phomopsis sojae Lehman, (Tabela 2), visto que a presença desse fungo está restrita, na maioria dos casos, apenas ao tegumento, causando variações nos resultados obtidos entre os testes de germinação e o conduzido na areia (FRANÇA NETO; HENNING, 1984).

Os resultados do teste de envelhecimento acelerado, para as sementes da cultivar Embrapa 48 (Tabela 1), não indicaram diferenças entre os tipos de colheitas e os teores de água. Esse mesmo teste, aplicado para as sementes da cultivar FTS Águia (Tabela 1), mostrou germinação superior para as sementes colhidas manualmente com $17,5 \%$ de água, em relação às colhidas mecanicamente com $14,7 \%$ e $12,7 \%$ de água.

A análise da sanidade das sementes de soja, para a cultivar Embrapa 48 (Tabela 2), mostrou incidência média de $63 \%$ para os fungos considerados como de campo (Cercospora kikuchii Tak. Matsumoto \& Tomoy, Fusarium semitectum Berk. \& Rav. e Phomopsis sojae Lehman), enquanto para as sementes da cultivar FTS Águia foi de 29,3\%. 


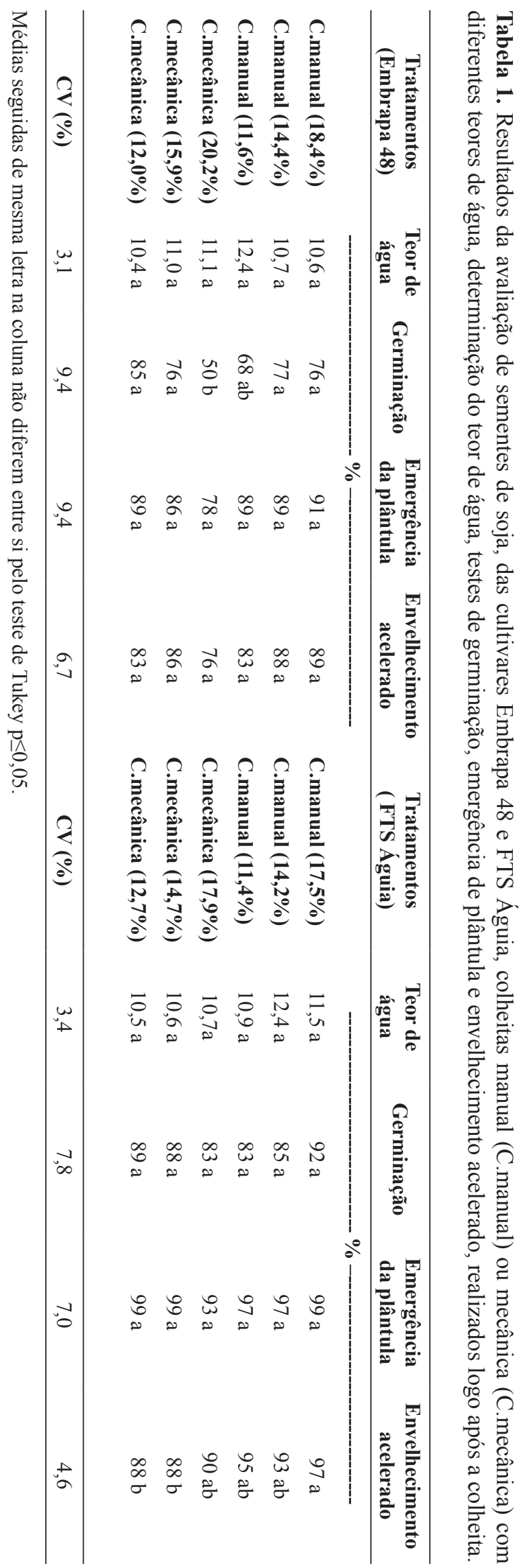




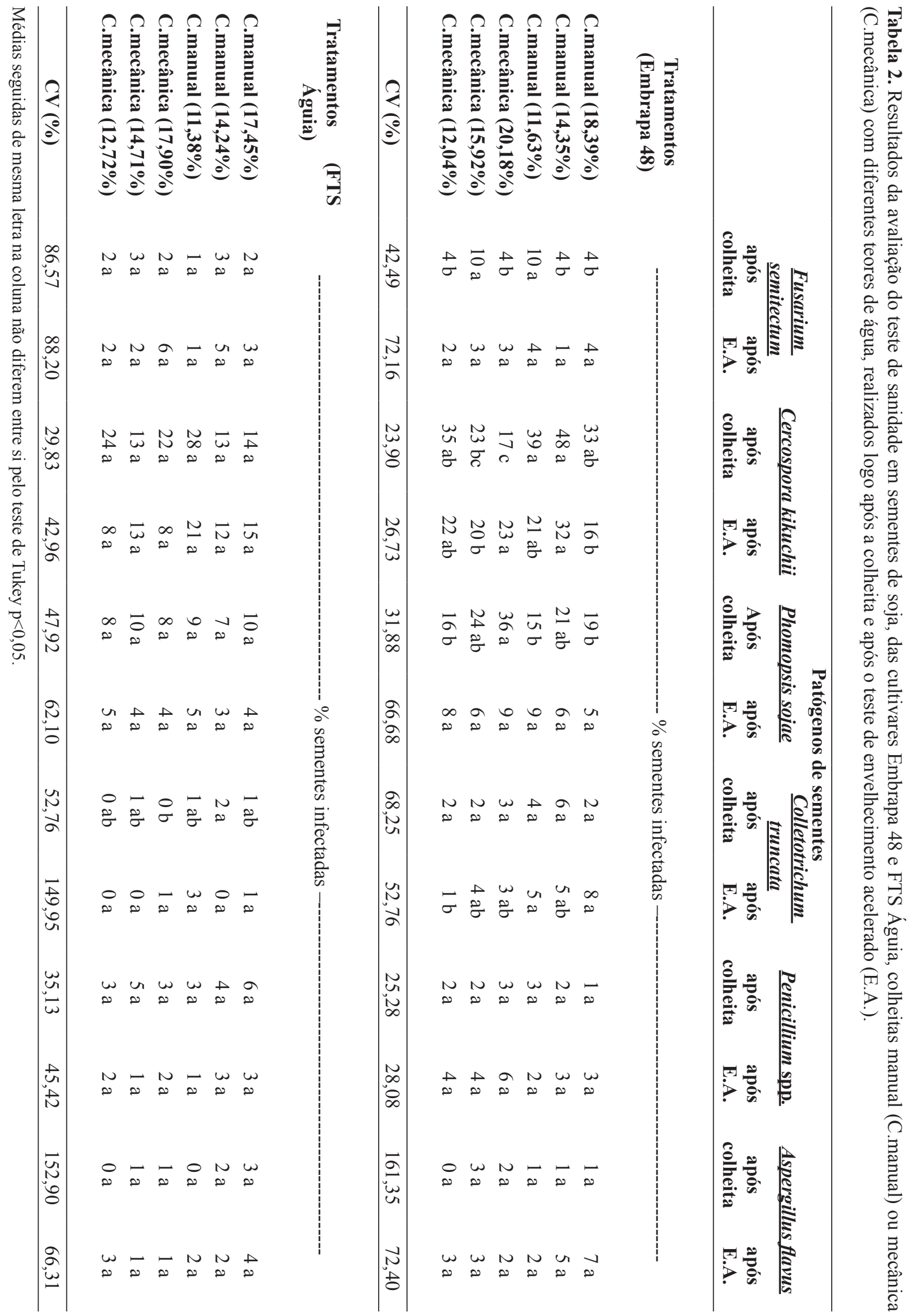


Por meio dos resultados obtidos na avaliação da sanidade das sementes foi possível obter parâmetros para verificar se a redução da germinação das sementes pode ser caracterizada pela presença de fungos. Ito e Tanaka, Menten e Marianno (1993) e França Neto et al. (2006), relataram que a presença de certos patógenos nas sementes pode causar efeitos diretos, como a redução do potencial germinativo das sementes.

Durante a produção das sementes em campo foi verificada quantidade significativamente alta de Phomopsis sojae Lehman. A infecção das sementes por $P$. sojae, foi beneficiada pela ocorrência de altas temperatura e umidade relativa do ar, durante a fase final de maturação das sementes; fato confirmado pelos resultados do teste de sanidade (Tabela 2). Foi possível observar, para as sementes da cultivar Embrapa 48 (colhidas à máquina com 20,2\% de água), uma menor porcentagem de germinação (Tabela 1) e maior incidência de $P$. sojae (Tabela 2). Para as sementes da cultivar FTS Águia a germinação foi estatisticamente semelhante para todos os tratamentos (Tabela 1), assim como os níveis de $P$. sojae nas sementes (Tabela 2).

Com o intuito de verificar se há relação entre o aumento da germinação das sementes e a redução da incidência dos patógenos, a sanidade das sementes foi avaliada após o teste de envelhecimento acelerado. Os resultados indicaram (Tabela 2) que houve redução das incidências de Cercospora kikuchii Tak. Matsumoto \& Tomoy e Phomopsis sojae Lehman nas sementes das duas cultivares. Confirmando que a presença desses patógenos contribuiu para a redução da germinação das sementes que não foram submetidas ao teste de envelhecimento acelerado.

Para os fungos Fusarium semitectum Berk. \& Rav. e Colletotrichum truncata Schw. Andrus \& Moore, que contaminaram a semente no campo (EMBRAPA, 2006), não houve diminuição significativa da incidência destes patógenos após o teste de envelhecimento acelerado (Tabela 2).
A análise da sanidade das sementes de soja, das cultivares Embrapa 48 e FTS Águia mostrou que, não houve evidência da interferência do método de colheita e nem do teor de água das sementes colhidas em relação aos microrganismos associados às sementes (Tabela 2). O que se pode verificar é que, em alguns casos, como para o fungo Cescospora kikuchii Tak. Matsumoto e Tomoy nas sementes da cultivar Embrapa 48 (Tabela 2), ocorreu maior incidência nas sementes colhidas manualmente. Estes resultados foram semelhantes aos apresentados por Costa, Mesquita e Heninng (1979), que observaram maior ocorrência de $C$. kikuchii em sementes colhidas manualmente, em comparação às colhidas à máquina. Para as sementes da cultivar FTS Águia, não foram observadas diferenças da infecção de C. kikuchii entre os tratamentos (Tabela 2).

Em relação aos fungos Phomopsis sojae Lehman e Colletotrichum truncata Schw. Andrus e Moore (Tabela 2), a incidência destes patógenos foi maior nas sementes da cultivar Embrapa 48, em comparação às da cultivar FTS Águia. A contaminação das sementes por P. sojae ocorre na fase final do ciclo da soja (EMBRAPA, 2006); sendo mais agressiva em sementes com menor teor de lignina no tegumento, pois contaminam as sementes através de orifícios do tegumento (OLIVEIRA; CARVALHO; PINHO, 1997). Observações similares foram feitas por Tanaka, Menten e Marianno (1989), inoculando sementes de algodão com Colletotrichum sp., observando que o contato das sementes com o inoculo, resultou na penetração do fungo pelo tegumento.

Observou-se redução na incidência de patógenos nas sementes de soja, das cultivares Embrapa 48 e FTS Águia, em função das condições de alta temperatura e umidade relativa do ar, que são utilizadas no teste de envelhecimento acelerado; especialmente para as sementes da cultivar FTS Águia, com maior teor de lignina no tegumento.

A redução dos patógenos constatada após o teste 
de envelhecimento acelerado contribuiu para o aumento da germinação nas sementes das cultivares Embrapa 48 e FTS Águia.

\section{Agradecimento}

À Fundação de Amparo a Pesquisa do Estado de São Paulo (FAPESP), pelo auxílio financeiro.

\section{Referências}

ALVAREZ, P. J. C.; KRZYZANOWSKI, F. C.; MANDARINO, J. M. G.; FRANÇA NETO, J. B. Relationship between soybean seed coat lignin content and resistance to mechanical damage. Seed Science and Technology, Zürich, v. 25, n. 2, p. 209-214, 1997.

BRACCINI, A. L.; REIS, M. S.; SEDIYAMA, C. S.; SEDIYAMA, T. Avaliação da qualidade fisiológica e sanitária da semente de genótipos de soja (Glycine max (L.) Merril) com diferentes graus de impermeabilidade do tegumento. Revista Brasileira de Sementes, Brasília, v. 16, n. 2, p. 195-200, 1994.

BRASIL. Ministério da Agricultura, Pecuária e Abastecimento. Secretaria de Defesa Agropecuária. Regras para análise de sementes. Brasília: Mapa/ACS, 2009. 399 p.

COSTA, N. P.; MESQUITA, C. M.; HENINNG, A. A. Avaliação das perdas e qualidade de semente na colheita mecânica de soja. Revista Brasileira de Sementes, Brasília, v. 1, n. 3, p. 49-58, 1979.

DE LEON, C.; GRUDLOYMA, U. Heat therapy of maize seed and its effect on viability. Indian Phytopathology, New Delhi, v. 47, n. 1, p. 89-91, 1994.

EMPRESA BRASILEIRA DE PESQUISA AGROPECUÁRIA - EMBRAPA. Tecnologias de produção de soja - região central do Brasil - 2007. Londrina: EMBRAPA, CNPSo, 2006. 225 p.
FRANÇA NETO, J. B.; HENNING, A. A. Qualidade fisiológica e sanitária de sementes de soja. Londrina: EMBRAPA, CNPSo, 1984. 39 p. (Circular Técnica, 9).

FRANÇA NETO, J. B.; KRZYZANOWSKI, F. C.; HENNING, A. A.; COSTA, N. P. Tecnologia da produção de sementes de soja de alta qualidade. Londrina: Foros, 2006. 5 p.

ITO, M. F.; TANAKA, M. A. S. Soja: principais doenças causadas por fungos, bactérias e nematóides. Campinas: Fundação Cargill, 1993. 48 p. (Série Técnica, 186).

KRZYZANOWSKI, F. C.; FRANÇA NETO, J. B.; HENNING, A. A. Relato dos testes de vigor disponíveis para as grandes culturas. Informativo ABRATES, Londrina, v. 1, n. 2, p. 11-14. 1991.

MARCOS FILHO, J.; CICERO, S. M.; SILVA, W. R. Avaliação da qualidade das sementes. Piracicaba: FEALQ, 1987. $230 \mathrm{p}$.

OBANDO FLOR, E. P.; CICERO, S. M.; FRANÇA NETO, J. B.; KRZYZANOWSKI, F. C. Avaliação de danos mecânicos em sementes de soja por meio da análise de imagens. Revista Brasileira de Sementes, Brasília, v. 26, n. 1, p. 68-76, 2004.

OLIVEIRA, J. A.; CARVALHO, M. L. M.; PINHO, E. V. R. V. Efeito do método de colheita na qualidade física, fisiológica e sanitária de sementes de milho. Revista Brasileira de Sementes, Brasília, v. 19, n. 2, p. 200-206, 1997.

RAJU, U. J.; SIVAPRAKASAM, K. Influence of seed treatment with fungicides, bactericide, hot water and antagonists on the seedling vigour of cabbage. Madras Agricultural Journal, Coimbatore, India, n. 76, p. 26-30, 1989.

SINCLAIR, J. B. Latent infection of soybean plants and seeds by fungi. Plant Disease, Saint Paul, v. 75, n. 3, p. 220-224, 1991.

TANAKA, M. A. S.; MENTEN, J. O. M.; MARIANNO, M. I. A. Inoculação artificial de sementes de algodão com Colletotrichum gossypii var. cephalosporioides e infecção das sementes em função do tempo de exposição ao patógeno. Summa Phytopathologica, Jaguariúna, v. 15, n. 2, p. 232-237, 1989. 
